This is the peer-reviewed version of the article:

Lojpur, V., Krstić, J., Kačarević-Popović, Z., Filipović, N., Validžić, I.L., 2018. Flexible and high-efficiency Sb2S3/solid carrier solar cell at low light intensity. Environmental Chemistry Letters 16, 659-664. https://doi.org/10.1007/s10311-017-0702-7

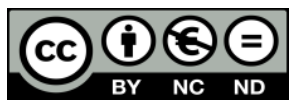

This work is licensed under the Attribution-NonCommercial-NoDerivatives 4.0 International (CC BY-NC-ND 4.0) 


\title{
Flexible and high-efficiency Sb2S3/solid carrier solar cell at low light intensity
}

Vesna Lojpur ${ }^{1}$, Jelena Krstić ${ }^{1}$, Zorica Kačarević-Popović ${ }^{1}$, Nenad Filipović ${ }^{2}$, Ivana Lj. Validžić $^{1 *}$

${ }^{1}$ University in Belgrade, Vinča Institute of Nuclear Sciences, P.O. Box 522, Belgrade 11001, Serbia

${ }^{2}$ Institute of Technical Sciences of SASA, Knez Mihailova 35/IV, Belgrade 11000, Serbia

\begin{abstract}
Producing green and efficient energy sources is a major challenge. As a consequence, the use of photovoltaic devices for conversion of light into electricity is growing worldwide. A lot of effort had been invested to create high-efficient solar cells, but their durability, stability, flexibility and efficiency at low light intensities are still unexplored. Here, we built a flexible solar cell made of p-doped, amorphized a-undoped and $\mathrm{n}$-doped $\mathrm{Sb}_{2} \mathrm{~S}_{3}$ solid carrier loaded with electrolyte. Indium tin oxide glass was the working electrode, and aluminium was the counter electrode. Every $(\mathrm{p}-\mathrm{a}-\mathrm{n})$ flexible $\mathrm{Sb}_{2} \mathrm{~S}_{3} /$ solid carrier layers were obtained using a cheap casting/solvent evaporation technique, from a blend consisted of chitosan, polyethylene glycol and electrolyte containing $0.5 \mathrm{M}$ potassium iodide and $0.05 \mathrm{M}$ iodine, and corresponding synthesized amorphized a-undoped and $\mathrm{p}$ and $\mathrm{n}$-doped $\mathrm{Sb}_{2} \mathrm{~S}_{3}$ semiconductor. Results show that flexible $\mathrm{Sb}_{2} \mathrm{~S}_{3}$ solar cell possesses good stability and efficiency of about $10 \%$ at $5 \%$ sun. Overall, our findings demonstrate for the first time that flexible solar cell can be made and used for low light intensity applications.
\end{abstract}

Keywords: Solar energy materials $\mathrm{Sb}_{2} \mathrm{~S}_{3}$ Solar cell Low light intensity Optics/lens

\section{Introduction}

The high demand for clean energy sources has fostered research, development and production of new solar cells (Kamat 2007). Inorganic silicon solar cells are still superior in the world market of photovoltaics with power efficiency of 15-20\% (mono-crystalline device) (Bagher 2014). The main problem with silicon solar cells is the production cost. A few decades ago,

\footnotetext{
*Ivana Lj. Validžić, validzic@vinca.rs
} 
organic photovoltaic solar cells were developed, but their expansion in research becomes higher with solar cells based on polymer thin films due to flexibility, lightweight, easy processing mechanisms and low-cost fabrications (Gunes et al. 2007). Despite many inventions and research, the best found efficiency for organic solar cells was 10\% (Ahmad et al. 2018). Recently, perovskite solar cells attracted a lot of attention since their accomplished efficiency was $22 \%$ (Ansari et al. 2018). However, stability is the crucial problem of these cells that is not overcome yet, so perovskite solar cells are still only on research level.

The amount of solar energy flux that comes on Earth depends on the latitude of the geographical area. The situation is that in some parts of USA, Africa, Middle East and Australia, the annual solar irradiation exceeds $1600 \mathrm{kWh} / \mathrm{m}^{2}$. Other parts of the Earth have solar irradiation far below, so it is of great importance to research and produce solar cells that can work at lower light intensities. Along with the creating and making new solar cells, efficiency at low light intensity is the main point of interest in our research.

There are many semiconductors that might be used for solar cells applications, and among them is antimony trisulphide $\left(\mathrm{Sb}_{2} \mathrm{~S}_{3}\right)$. Antimony trisulphide $\left(\mathrm{Sb}_{2} \mathrm{~S}_{3}\right)$ is important member of V-VI group semiconductors, which useful properties make it promising candidate for important applications in diverse area such as solar energy conversion due to its good photoconductivity, thermoelectric cooling technology and photoelectronics in the infrared (IR) region (Yu et al. 2006; Bao et al. 2007).

Recently, we reported solar cells that are made/based entirely on synthesized undoped and doped $\mathrm{Sb}_{2} \mathrm{~S}_{3}$ semiconductor (Lojpur et al. 2017a, b; Validžic et al. 2016; Janoševic et al. $2016 \mathrm{a}, \mathrm{b}, \mathrm{c})$. Here, we report, for the first time, flexible solar cell made of three layers, i.e. solid carriers. In first layer, $\mathrm{Sb}_{2} \mathrm{~S}_{3}$ is doped with copper, in second it is undoped with amorphized $\mathrm{Sb}_{2} \mathrm{~S}_{3}$, while in third layer $\mathrm{Sb}_{2} \mathrm{~S}_{3}$ is doped with selenium. Indium tin oxide glass was used as a working electrode and aluminium as the counter electrode, while flexible $\mathrm{Sb}_{2} \mathrm{~S}_{3}$ solid carrier was loaded with electrolyte. As far as we are aware, no similar reported cell was found in the literature. 


\section{Materials and methods}

All chemicals, chitosan ( $\mathrm{Mw}=95 \mathrm{kDa}$, Sigma-Aldrich), acetic acid (Alkaloid Skoplje), polyethylene glycol $(\mathrm{Mw}=3350 \mathrm{Da}$, Sigma-Aldrich), potassium iodide and iodine (SigmaAldrich) were used without further purification. Detail synthesis procedures of $\mathrm{p}-$, amorphized a-undoped and $\mathrm{n}-\mathrm{Sb}_{2} \mathrm{~S}_{3}$ nanoparticles and used materials have been described previously many times (Lojpur et al. 2017a, b; Validžic et al. 2016; Janoševic et al. 2016a, b, c).

The $3 \%$ chitosan solution was obtained by dissolving chitosan in $1 \mathrm{M}$ acetic acid solution at room temperature under the constant stirring for $3 \mathrm{~h}$. Then, $3 \%$ aqueous solution of polyethylene glycol and potassium iodide/iodine $(1.5 / 0.15 \mathrm{M})$ was added in order to prepare a solution in which the volume ratios of chitosan/polyethylene glycol (potassium iodide/iodine) were $(5 / 1 / 1 \mathrm{v} / \mathrm{v})$. Finally, $0.6 \mathrm{~g}$ of p-, amorphized a-undoped and $\mathrm{n}$-doped $\mathrm{Sb}_{2} \mathrm{~S}_{3}$ was put in the solution and left for constant stirring for $2 \mathrm{~h}$. The obtained final solution was poured into Petri dishes and left to evaporate at room temperature. After drying in the air and in the hothouse at $40{ }^{\circ} \mathrm{C}$, each sulphide solid carrier was placed in a hydraulic press (4 Tones) and left over night (20 h).

Thermogravimetric analysis was conducted on the Setsys Evolution (Setaram, France) in the atmosphere of synthetic air (flow rate $20 \mathrm{ml} / \mathrm{min}$ ). The phase transitions were investigated on SETARAM apparatus differential scanning calorimetry (DSC) EVO 131. The X-ray diffraction (XRD) patterns were obtained on a Philips PW-1050 using $\mathrm{CuK} \alpha$ radiation with a fixed $1^{\circ}$ divergence and $0.1^{\circ}$ receiving slits. The power output characteristics were obtained by Keithley 181 nanovoltmeter, 230 programmable voltage source and 195 A digital millimeter.

\section{Results and discussion}

The designed cell architecture is presented schematically in Fig. 1. The figure also shows an image of a thick (around $1 \mathrm{~mm}$ ) p-doped, amorphized a-undoped and n-doped [marked with (p), (a) and (n)] flexible $\mathrm{Sb}_{2} \mathrm{~S}_{3}$ /solid carriers. Solid carriers are extremely flexible, and after filling with electrolyte, their softness allows good contacts in the cell. 
The thermogravimetric analysis (TGA)/differential scanning calorimetry (DSC) was used to investigate the thermal characteristics/stability of obtained flexible solid carrier. These samples were recorded with the same composition but without the synthesized powders, pdoped, amorphized a-undoped and n-doped $\mathrm{Sb}_{2} \mathrm{~S}_{3}$ present in the initial blend. Differential scanning calorimetry measurements of pure polyethylene glycol and solid carrier were performed, and the results are shown in Fig. 2A.

Chitosan usually does not undergo through phase transition prior to decomposition. For pure polyethylene glycol, a broad endothermic peak was observed at around $60{ }^{\circ} \mathrm{C}\left(\mathrm{T}_{\mathrm{m}}\right)$ (Sharma et al. 2016), and for three component blend, the peak was shifted to higher-temperature region, at around $95{ }^{\circ} \mathrm{C}$. The thermogravimetric analyses for unused (A) and used (B) three component blend (Fig. 2B) showed a slight weight loss up to $50^{\circ} \mathrm{C}$. More significant weight loss for blend was noticed between 80 and $120^{\circ} \mathrm{C}$ that probably come from dehydration. As far as we are aware, there are no literature reports of such blend.

Used/unused solid carrier consists of polyethylene glycol, chitosan and electrolyte potassium iodide/iodine, and X-ray diffraction patterns of starting components polyethylene glycol and chitosan as well as used and unused solid carrier without the presence of synthesized $\mathrm{Sb}_{2} \mathrm{~S}_{3}$ are presented also in Fig. 2 ( $\mathrm{C}$ and enlarged $\mathrm{C}_{1}$ ). Several peaks of polyethylene glycol were observed which confirmed its crystalline nature, while for chitosan partially crystalline nature is evident for the sample. As can be seen, unused solid carrier becomes completely amorphous. This is partly due to the fact that the presence of electrolyte potassium iodide/iodine reduces crystallinity due to the salt since cation $\mathrm{K}^{+}$has a large radius. However, after a few months of using of the solid carrier, the electrolyte begins to crystallize in the form of potassium iodide, which is shown in Fig. $2\left(\mathrm{C}\right.$ and $\left.\mathrm{C}_{1}\right)$. The softness of the layers of solar cells makes it be applicable in a lot of different surfaces. The ability of adaptation to the surface is another advantage of these types of solar cells.

Typical illuminated $I-V$ curves for fabricated cells under low illumination of $5 \%$ sun are shown in Fig. 3A. Two cells (3A up and down) were made to be the same. The efficiency $\eta$ (in \%) was calculated from the well-known relation $\eta=V_{\mathrm{OC}} I_{\mathrm{SC}} \mathrm{FF} / P_{\text {input }} \times 100$, where $P_{\text {input }}$ is the input light energy. The efficiency of the cells is 9.3 and $11.3 \%$ for $5 \%$ sun. An optical/lens system, handmade, was interposed between the lamp and the cell to prevent heating of the cell and decreases light intensity. The illuminated surfaces of the cells are $3 \mathrm{~cm}^{2}$, while the total 
surface of all the cell was $7.5 \mathrm{~cm}^{2}$. The optic/lens system is made of two curved glass lenses (two convex surfaces in spherical form) through which circulates continuously cold water. Water pipes are integrated inlets and outlets of the lens, while at the same time, the system is completely closed and safe for work. In all our experiments, temperature effect is totally abolished by using lens/optic system with flow water layer (Lojpur et al. 2017a, b, c). Detail lens/optic system with improved photovoltaic characteristics for so far designed solar cells is given in our previous published paper (Lojpur et al. 2018). With no temperature effect and lens/optic system, we were able to obtain repeatable results with the same efficiency. Figure 3B shows a spectra of the used tungsten filament lamp, and rounded part of the spectrum represents dominant narrow energy part of the photons from 550 to $600 \mathrm{~nm}$ that arrives at the surface of the solar cell. The dependence of the relative transmittance of optic/lens compared to transmittance of the lamp without optic/lens on wavelengths is also shown in Fig. 3C. Obtained results indicate minimal permeability in the UV region (up to $375 \mathrm{~nm}$ ) and almost constant value in visible and NIR regions. Using of lens/optic system with flow water layer that changes the spectrum enables the application of these solar cells in majority conditions present on Earth with low light irradiation.

The current-voltage $(I-V)$ characteristics of the made cell, in the dark and illuminated by light ( $5 \%$ sun), as well as variation in the short-circuit current $\left(I_{\mathrm{SC}}\right)$ and the open-circuit voltage $\left(V_{\mathrm{OC}}\right)$ with time, are shown in Fig. 4. After illumination, the shift of the current-voltage $(I-V)$ curves into the fourth quadrant shows that the cell worked as an electricity generator. The photovoltage and photocurrent rise and decay curves reveal that the decrease is quite a slow process.

Typical solar cell has a $\mathrm{p}-\mathrm{a}-\mathrm{n}$ diode structure, similar to amorphous silicon solar cell (Rech and Wagner 1999) where $\mathrm{p}, \mathrm{n}$ and a (or i) refer to doped and intrinsic (undoped) layers. The light is entering through the p-layer, which efficiently supports hole collection in the device. A transparent conductive oxide (indium tin oxide, ITO) film contacts the diode from the front side, and, in the simplest case, a metal film serves both as rear contact and back reflector. Thick p-doped and n-doped layers build up an electric field over the intrinsic/undoped layer. Electrons and holes generated in the undoped layer are driven to the $n$ and p-layer, respectively, by the internal electric field. It should be noted that the made cell without extra electrolyte loaded in every layer works as an electricity generator but with lower values of photocurrent and reduced efficiency (not shown). 


\section{Conclusion}

In summary, for the first time we presented the designed solar cell that consists of indium tin oxide/p and n-doped and amorphized (a) undoped flexible $\mathrm{Sb}_{2} \mathrm{~S}_{3} /$ solid carrier loaded with electrolyte/aluminium as the counter electrode. Each of the layers was obtained by a cheap casting/solvent evaporation technique. We also presented that the cell exhibits quite high efficiency at the very low light intensity and suitable distribution which is achieved through the use of optics/lens system. It has been found that the processes in a cell are the same as in each $\mathrm{p}-\mathrm{a}-\mathrm{n}$ junction and that the presence of electrolyte facilitates and speeds up the transfer of charge through the cell.

Acknowledgements: This work is supported by the Ministry of Education, Science and Technological Development of the Republic of Serbia (Project 45005).

\section{References}

1. Ahmad Z, Najeeb MA, Shakoor RA, Al-Muhtaseb SA, Touati F (2018) Limits and possible solutions in quantum dot organic solar cells. Renew Sustain Energy Rev 82:1551-1564. https://doi.org/10.1016/j.rser.2017.07.001

2. Ansari MIH, Qurashi A, Nazeeruddin MK (2018) Frontiers, opportunities, and challenges in perovskite solar cells: a critical review. J Photochem Photobiol, C 35:1-24. https://doi.org/10.1016/j.jphotochemrev.2017.11.002

3. Bagher AM (2014) Introduction to organic solar cells. Sustain Energy 2:85-90. https://doi.org/10.12691/rse-2-3-2

4. Bao H, Cui X, Li CM, Song Q, Lu Z, Guo J (2007) Synthesis and electrical transport properties of single-crystal antimony sulfide nanowires. J Phys Chem C 111:1713117135. https://doi.org/10.1021/jp076828q

5. Gunes S, Neugebauer H, Sariciftci NS (2007) Conjugated polymer- based organic solar cells. Chem Rev 107:1324-1338. https://doi.org/10.1021/cr050149z

6. Janošević V, Mitrić M, Bundaleski N, Rakočević Z, Validžić ILj (2016a) High-efficiency $\mathrm{Sb}_{2} \mathrm{~S}_{3}$ - based hybrid solar cell at low light intensity: cell made of synthesized $\mathrm{Cu}$ and $\mathrm{Se}-$ doped $\mathrm{Sb}_{2} \mathrm{~S}_{3}$. Prog Photovolt Res Appl 24:704-715. https://doi.org/10.1002/pip.2724 
7. Janošević V, Mitrić M, Savić J, Validžić ILj (2016b) Structural, optical, and electrical properties of applied amorphized and polycrystalline $\mathrm{Sb}_{2} \mathrm{~S}_{3}$ thin films. Metall Mat Trans A 47:1460-1468. https://doi.org/10.1007/s11661-015-3282-9

8. Janošević V, Mitrić M, Janošević-Ležaić A, Validžić ILj (2016c) Weak light performance of synthesized amorphous $\mathrm{Sb}_{2} \mathrm{~S}_{3}$-based hybrid solar cell. IEEE J Photovolt 6:473-479. https://doi.org/10.1109/JPHOTOV.2015.2501731

9. Kamat PV (2007) Meeting the clean energy demand: nanostructure architectures for solar energy conversion. J Phys Chem C 111:2834-2860. https://doi.org/10.1021/jp066952u

10. Lojpur V, Tasić N, Validžić ILj (2017a) Different behaviors in current-voltage measurements of undoped and doped $\mathrm{Sb}_{2} \mathrm{~S}_{3}$-based solar cells. J Appl Electrochem 47:117-124. https://doi.org/10.1007/s10800-016-1025-2

11. Lojpur V, Mitrić M, Kačarević-Popović Z, Radosavljević A, Rakočević Z, Validžić ILj (2017b) The role of low light intensity: a cheap, stable, and solidly efficient amorphous $\mathrm{Sb}_{2} \mathrm{~S}_{3}$ powder/hypericin composite/PVA matrix loaded with electrolyte solar cell. Environ Prog Sustain Energy 36:1507-1516. https://doi.org/10.1002/ep.12597

12. Lojpur V, Krstić J, Kačarević-Popović Z, Mitrić M, Rakočević Z, Validžić ILj (2017c) Efficient and novel $\mathrm{Sb}_{2} \mathrm{~S}_{3}$ based solar cells with chitosan/poly(ethylene glycol)/electrolyte blend. Int J Energy Res. https://doi.org/10.1002/er.3899

13. Lojpur V, Mitrić M, Validžić ILj (2018) The role of low light intensity: a step towards understanding the connection between light, optic/lens and photovoltaic behavior for $\mathrm{Sb}_{2} \mathrm{~S}_{3}$ thin-film solar cells. Opt Laser Technol 101:425-432. https://doi.org/10.1016/j.optlastec.2017.11.045

14. Rech B, Wagner H (1999) Potential of amorphous silicon for solar cells. Appl Phys A 69:155-167. https://doi.org/10.1007/s003390050986

15. Sharma RK, Ganesan P, Tyagi VV, Mahlia TMI (2016) Accelerated thermal cycle and chemical stability testing of polyethylene glycol (PEG) 6000 for solar thermal energy storage. Sol Energy Mater Sol Cells 147:235-239. https://doi.org/10.1016/j.solmat.2015.12.023

16. Validžić ILj, Janošević V, Mitrić M (2016) Characterization and current-voltage characteristics of solar cells based on the composite of synthesized $\mathrm{Sb}_{2} \mathrm{~S}_{3}$ powder with small band gap and natural dye. Environ Prog Sustain Energy 35:512-516. https://doi.org/10.1002/ep.12221 
17. Yu Y, Wang RH, Chen Q, Peng LM (2006) High-quality ultralong $\mathrm{Sb}_{2} \mathrm{Se}_{3}$ and $\mathrm{Sb}_{2} \mathrm{~S}_{3}$ nanoribbons on a large scale via a simple chemical route. J Phys Chem B 110:1341513419. https://doi.org/10.1021/jp061599d 


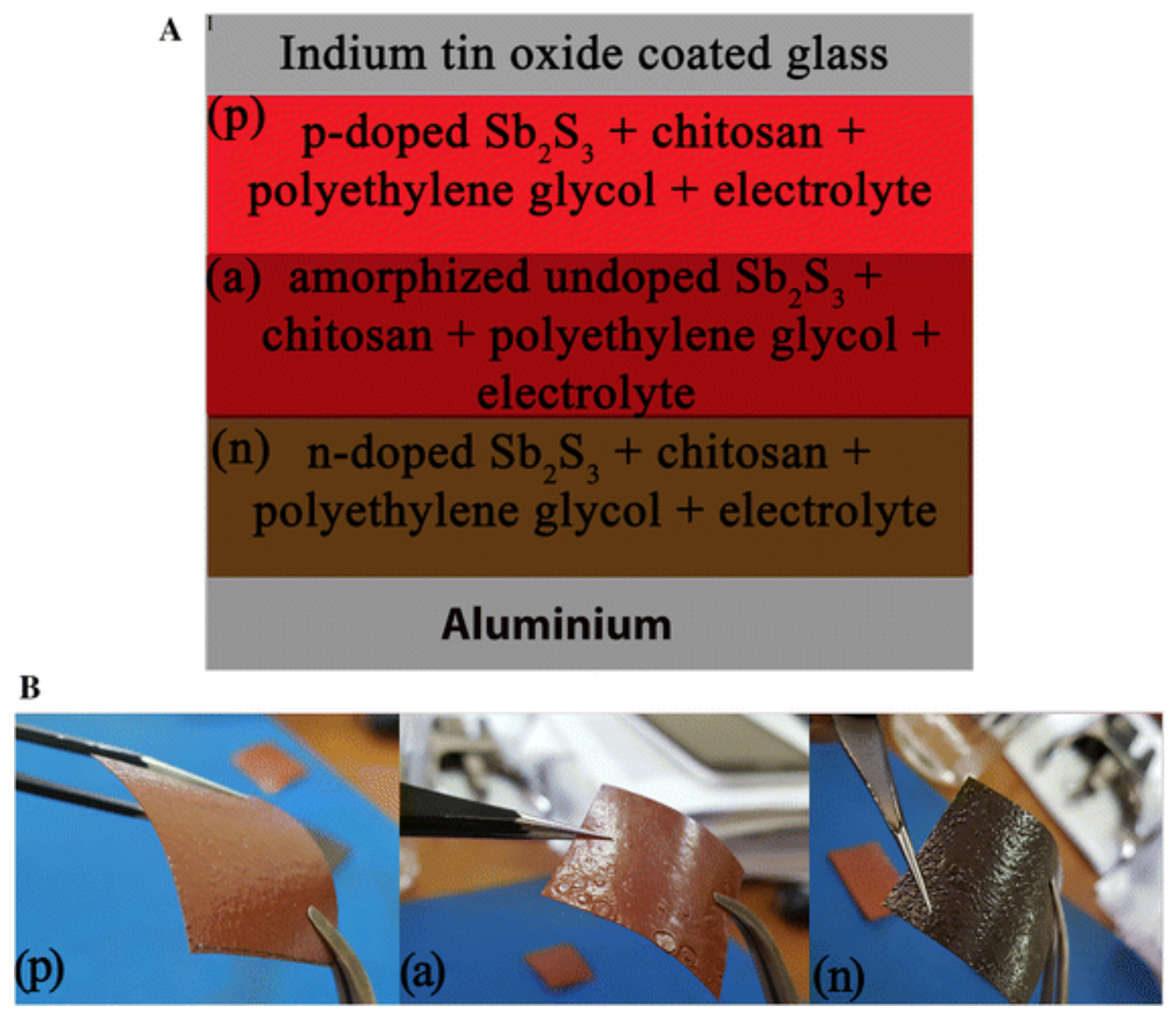

Figure $1 \mathrm{~A}$ schematic of designed cell with the exact composition of each of the flexible $\mathrm{Sb}_{2} \mathrm{~S}_{3} /$ solid layer (A), and photographs of designed flexible layers marked as (p), (a) and (n) (B). $\mathrm{Sb}_{2} \mathrm{~S}_{3}$ solid layers are extremely flexible and after filing with electrolyte their softness allows good contacts in the cell 

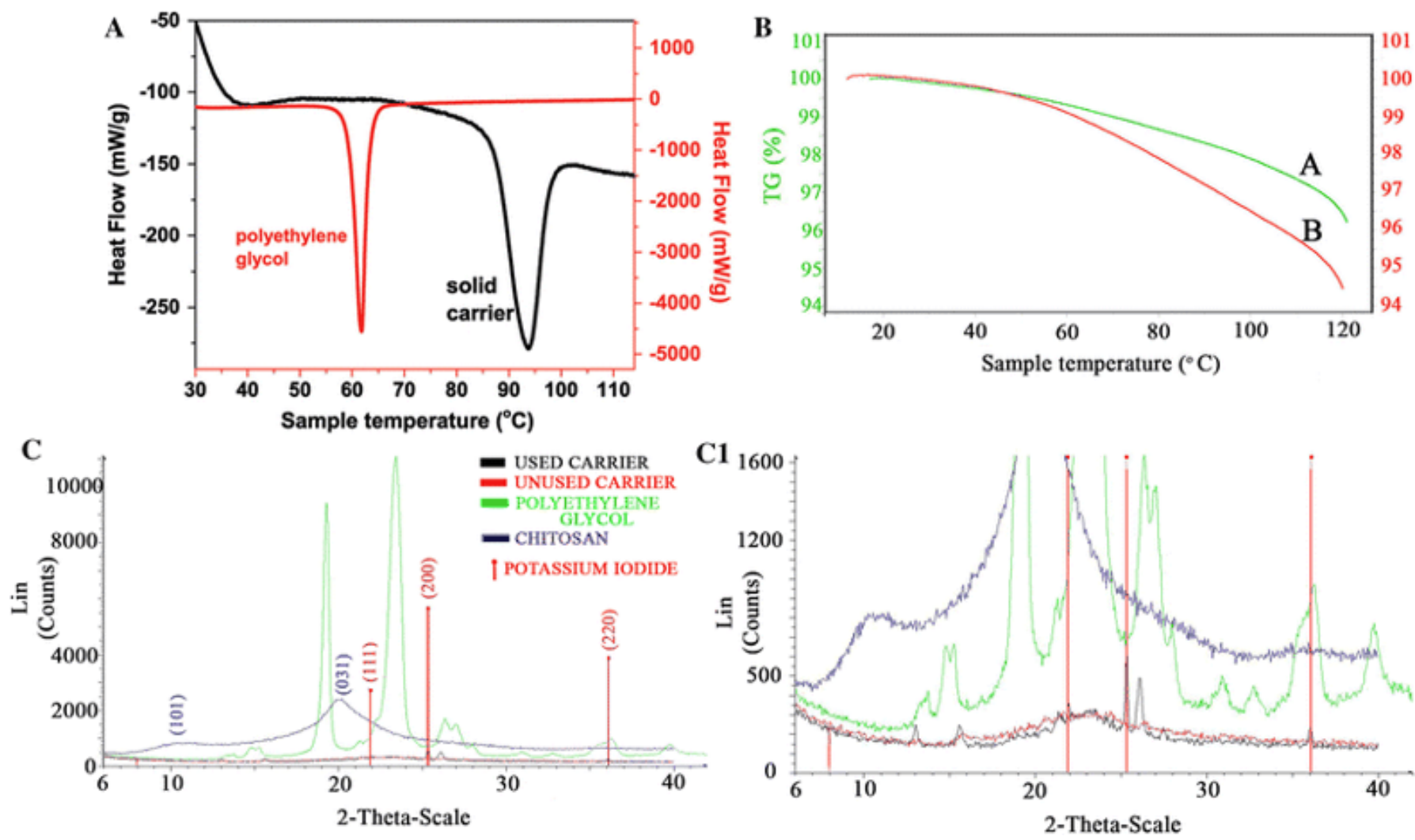

Figure 2 Differential scanning calorimetry (DSC) curves of polyethylene glycol and solid carrier with no $\mathrm{Sb}_{2} \mathrm{~S}_{3}$ present (endo. down) (A); thermogravimetric (TG) curves of unused (A) and used (B) solid carrier (B); X-ray diffraction patterns for used and unused carrier, polyethylene glycol and chitosan $\left(\mathbf{C}\right.$ and enlarged $\mathbf{C}_{1}$ ). Red bars indicate diffraction peaks of the potassium iodide. Corresponding planes for chitosan and potassium iodide are given, while the structure of polyethylene glycol is not resolved 

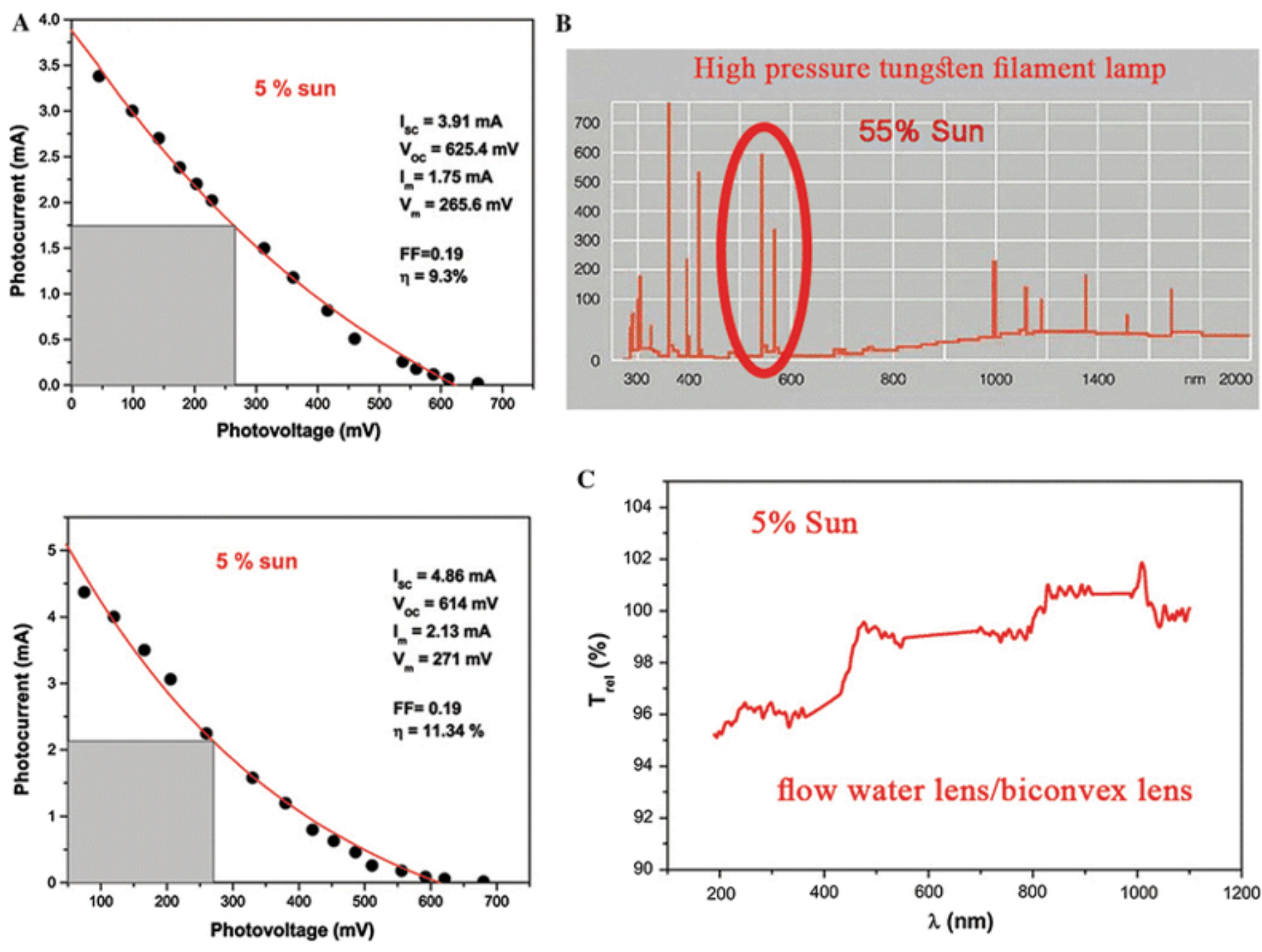

Figure 3 Illuminated current-voltage $(I-V)$ curves for designed solar cell (A); spectra of tungsten lamp and rounded dominant part of the spectrum reaching the surface of the cell after passing through the optic/lens system (B); the dependence of relative transmittance of optic/lens compared to transmittance of lamp without optic/lens on wavelengths $(\mathbf{C})$ 

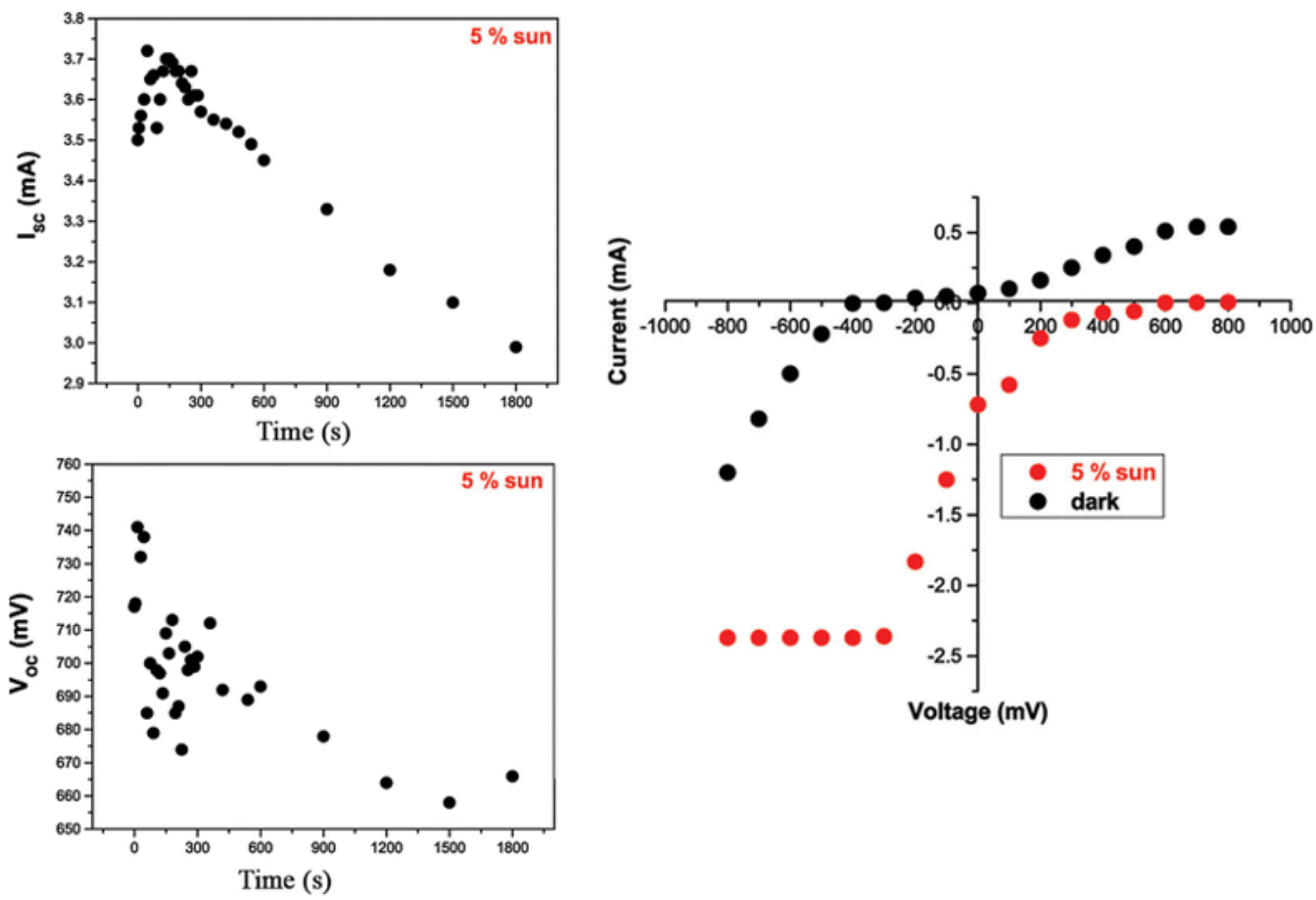

Figure 4 Variations in the short-circuit current $\left(I_{\mathrm{SC}}\right)$ and the open-circuit voltage $\left(V_{\mathrm{OC}}\right)$ with time as well as current-voltage $(I-V)$ characteristics in dark and illuminated by the low light intensity of $5 \%$ of the sun for made solar cell. The photovoltage and photocurrent rise and decay curves reveal that the decrease is quite a slow process, while the current-voltage $(I-V)$ curves after illumination shift into the fourth quadrant, revealing that the cell worked as an electricity generator 